\title{
ORIGINAL
}

ARTICLES

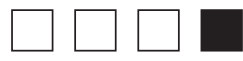

\section{Postresidency Impact of Alcohol and Drug Screening and Intervention Training}

J. Aaron Johnson, PhD; Sylvia Shellenberger, PhD; Christopher Buchanan, MD; Nicholas Cline, MD; Mary Velasquez, PhD; Kirk Von Sternberg, PhD; John Roxborough IV, MD; J. Paul Seale, MD

BACKGROUND AND OBJECTIVES: Many residency programs provide alcohol and drug screening, brief intervention (BI), and referral to treatment (SBIRT) training, hoping to impact residents' future practice activities. Little is known about postresidency use of these skills. This study assesses postresidency impact of SBIRT training.

METHODS: Over 3 years, physicians who participated in SBIRT training in four residency programs were recruited for follow-up. Participants chose between a paper and online questionnaire 12-24 months after graduation; participants received $\$ 20$ gift cards. We first analyzed postresidency responses only $(n=74)$, then compared pre- and posttraining results of those completing both surveys $(n=50)$.

RESULTS: Of 182 enrolled graduates, 74 (41\%) completed questionnaires. In paired comparisons to their pretraining responses, graduates increased endorsement of statements that Bls can reduce risky use and reduced endorsement of statements that they do not have adequate training or time to address patients' alcohol use, or that discussing alcohol use with patients is uncomfortable. While most barriers to providing interventions were endorsed less frequently by SBIRT-trained clinicians in postresidency surveys, ongoing concerns included poor reimbursement, little time, low success rates, and some discomfort with interventions. Seventy percent of graduates felt motivational interviewing techniques created stronger doctor-patient relationships; $16 \%$ reported colleagues in their practices had increased SBIRT activities after they joined the practice.

CONCLUSIONS: SBIRT trainees reported high levels of SBIRT activity 12-24 months after graduation and increased SBIRT activities by their colleagues. While some barriers remain, residency training appears to be a promising approach for disseminating SBIRT into clinical practice.

(Fam Med. 2022;54(3):200-6.)

doi: 10.22454/FamMed.2022.860266

nhealthy use of alcohol, nicotine, and illicit and prescription drugs cost Americans more than $\$ 740$ billion a year in increased health care costs, crime, and lost productivity. ${ }^{1}$ Every year, illicit and prescription drugs and alcohol contribute to the death of more than 130,000 Americans. ${ }^{2}$ In 2019, 36 million Americans admitted to past-month illicit drug use, and of the 140 million past-month alcohol users, nearly half (47\%) reported binge drinking. ${ }^{3}$ Despite the significant costs associated with substance use, the high prevalence of acute and chronic substance misuse, and a Class B recommendation by the United States Preventive Services Task Force for alcohol screening and brief counseling of adults in primary care, ${ }^{4}$ physicians often fail to address at-risk drinking and drug use in their patients. ${ }^{5-10}$ Data collected in 2017 by the Centers for Disease Control and Prevention (CDC) show that only $37.8 \%$ of adults were asked about binge drinking during a health checkup during the past 2 years, and only $20.1 \%$ of current binge drinkers had been advised to reduce or quit drinking. ${ }^{10}$ Similarly, Glass et al, using data from the National Survey on Drug Use and Health, found that among individuals with alcohol abuse or dependence who received an alcohol assessment in primary care, only $2.9 \%$ and $7.0 \%$, respectively, were offered information about treatment. ${ }^{11}$

From Augusta University, Augusta, GA (Drs Johnson and Seale); Mercer University School of Medicine, Macon, GA (Drs Shellenberger and Seale); University of Florida, College of Medicine, Gainesville, FL (Dr Buchanan); The University of Tennessee Health Science Center College of Medicine, Memphis, TN (Dr Cline); The University of Texas at Austin Steve Hicks School of Social Work, Austin, TX (Drs Velasquez and Kirk); and Unity Health Care, Washington, DC (Dr Roxborough). 
Since 2008 the Substance Abuse and Mental Health Services Administration (SAMHSA) has provided funding to more than 150 health professional training programs (colleges/ universities and community-based residency programs) in an effort to increase alcohol and drug screening and brief intervention in health care practices. ${ }^{12}$ The goal of these grants was to train future health care providers to identify and address unhealthy alcohol and drug use through a process known as Screening, Brief Interventions, and Referral to Treatment (SBIRT), in hopes that they would carry these skills into their future practices. ${ }^{13-17}$ Feasibility studies from the early phases of these projects determined that infusing SBIRT curriculum into existing training programs was indeed possible. ${ }^{13-15,18-24}$ The progress of developing and implementing curricula that yielded changes in resident attitudes and behaviors has been substantial. Residents not only reported satisfaction with training, ${ }^{13-14}$, ${ }_{17,25}$ they also demonstrated improvements in knowledge. ${ }^{22,25,26}$ Chart reviews conducted in residency clinics where training had been implemented also demonstrated significant increases in the use of validated screening instruments and the provision of brief interventions. ${ }^{27}$ Furthermore, immediately after SBIRT training, ${ }^{24}$ at 6 months posttraining ${ }^{17}$ and at 12 months posttraining, ${ }^{25}$ residents reported increased confidence in use and likelihood of incorporating SBIRT into their clinical practices. To date, however, there has been little effort to determine whether these significant improvements in SBIRT knowledge, skills, and performance during training years translated into the use of SBIRT in postgraduation practices. This study first examined data collected from SBIRT-trained primary care residents $12-24$ months postgraduation to determine the extent to which they had implemented SBIRT in their new practices.

\section{Methods}

\section{SBIRT Training}

Family medicine and internal medicine residents at seven sites in the southeastern United States participated in longitudinal SBIRT training that spanned 3 years and included 18 hours of content. The content focused on unhealthy alcohol and prescription and illicit drug use with approximately 5 hours dedicated to each substance category. Additional sessions focused on development of motivational interviewing skills and implementation of SBIRT in future practices (conducted with residents in the month prior to graduation). Didactic information, video examples, and role-play practice sessions were a part of each resident's training. Within participating residency clinics, universal screening was implemented so that patients at each site were screened at least yearly using single-question screens for alcohol and drugs ${ }^{28-29}$ with subsequent use of the Alcohol Use Disorders Identification Test ${ }^{30}$ and/or Drug Abuse Screen Test ${ }^{31}$ for follow-up if initial screens were positive. Residents were trained to use information from the screens to perform a structured brief intervention modeled after the Brief Negotiated Interview ${ }^{32,33}$ and to follow up with patients during continuity of care visits.

\section{Study Design}

Of the participating sites, four were recruited and began SBIRT training in 2010, while the remaining three were recruited and began SBIRT training in 2012. Prior to SBIRT training, residents at each participating site were asked to complete a baseline questionnaire $(\mathrm{N}=208)$. Baseline results were previously published. ${ }^{16}$ After completing SBIRT training and before graduation, residents were asked to provide followup contact information. Then, over a 3 -year period beginning in January 2012 , graduating residents from the four original SBIRT training sites were contacted 12-24 months after graduation and asked to complete a paper or web-based questionnaire (mode of administration was their choice). This questionnaire included many items from the baseline questionnaire, as well as additional information about their current practice setting. Initial contacts were through an email that included a link to the web-based questionnaire. Nonrespondents were contacted by telephone and directed to the web-based questionnaires. Upon request, questionnaires were mailed to respondents along with a self-addressed stamped envelope. Residents completing the questionnaire received $\$ 20$ gift cards. Of 182 graduating residents, 155 (85\%) had completed the baseline survey and $74(41 \%)$ completed the postresidency questionnaire. The Institutional Review Boards of each participating institution approved the study, and all participants gave written informed consent.

\section{Study Measures}

This questionnaire collected information on current screening and brief intervention practices as well as attitudes toward and confidence in identifying and addressing patients' alcohol and drug use. Most measures were standardized using multiitem measures from previous studies. ${ }^{15,34}$ Both the baseline and postresidency questionnaires required approximately 15 minutes to complete. The graduate questionnaire was comprised of 89 items, including (1) clinician's type of practice setting; (2) screening methods, if any, that were used at the site before the clinician began practicing there; (3) colleagues' increase, if any, in screening activity as a result of respondent's joining the group; (4) screening, brief intervention, and referral approaches used by the clinician; (5) of the last 50 patients seen, the number of patients the clinician counseled to cut back or quit their alcohol or drug use; (6) the number of 
minutes the clinician typically spent discussing alcohol or drug use with at-risk patients; (7) the importance to the clinician of various aspects of SBIRT practice in making a decision about whether to discuss the patient's alcohol or drug use, (Likert-type response format from 1 to 5 -extremely important to not important); and (8) types of interventions discussed with patients who are willing to cut down or quit using alcohol or drugs (Likert-type response from 1 to 5 -never to always).

\section{Analyses}

We analyzed surveys of the SBIRTtrained primary care residents $12-24$ months postgraduation to determine the extent to which they had implemented SBIRT in their new practices $(n=74)$. Results are reported as percentages. For Likert scale responses, we combined the "usually" and "always" categories. Results of these items reflect the percentage of physicians who selected one of these two categories. Next, we compared responses of all physicians surveyed postresidency with results of all residents surveyed pretraining $(\mathrm{n}=208)$. We performed additional analyses with the smaller number of respondents $(n=50)$ who completed both pre- and posttraining questionnaires. We used a paired samples $t$ test to identify statistically significant pre/ post differences in attitudes toward working with patients who use alcohol or drugs.

\section{Results}

None of the physicians entered solo practice following graduation. Small percentages joined urgent care $(\mathrm{n}=3$, $4.1 \%)$ or hospitalist groups $(\mathrm{n}=10$, $13.5 \%$ ) with equal numbers joining single or multispecialty groups $(\mathrm{n}=30,40.6 \%)$ or moving into fellowships ( $\mathrm{n}=31,41.9 \%)$.

\section{Screening Practices}

Physicians were asked to report how frequently they screened for at-risk alcohol use and drug use during the initial patient visit, during acute care visits, and during chronic care visits. Results presented are the percentage of physicians who reported that they usually or always screen during these types of visits (Table 1). Patients were most likely to be screened for at-risk alcohol and drug use during the initial visit. Screening was less common for acute care or chronic care visits.

Nearly half of the physicians (48.6\%) reported that their current practice site was not using a validated alcohol or drug screening tool prior to their joining the practice, while $16 \%$ reported that their colleagues in the practice had increased SBIRT activities as a result of their joining the practice. The alcohol screening instrument most often used by physicians was the $\mathrm{CAGE}^{35}$ (46.7\%), while $25.3 \%$ reported using quantity/frequency questions, and $18.7 \%$ used the single alcohol screening question. For drug screening, the most commonly reported instruments used were the single drug screening question (43.4\%), which has been validated for at-risk drug use, ${ }^{25}$ and quantity/frequency questions ( $34.2 \%$, Table 2).

Physicians reported having alcohol (55\%) and drug (43\%) screening questions included as part of the routine vital signs, with similar percentages reporting that these systems were standardized to ensure patients are rescreened for alcohol and drug use at least annually (50\% alcohol and $45 \%$ for drug use).

Table 1: Percentage of Postresidency Physicians Reporting "Usually" or "Always" Screening at Initial, Acute Care, or Chronic Care Patients' Visits

\begin{tabular}{|l|c|c|}
\hline \multicolumn{1}{|c|}{ Visit Type } & Alcohol Screening (\%) & Drug Screening (\%) \\
\hline Initial visits & 77.0 & 76.1 \\
\hline Acute care visits & 18.9 & 16.7 \\
\hline Chronic care visits & 52.8 & 45.8 \\
\hline
\end{tabular}

Table 2: Percentage of Postresidency Physicians Reporting Which Screening Instrument Is Used in Their Practice

\begin{tabular}{|l|c|c|}
\hline \multicolumn{1}{|c|}{ Screening Instrument } & Alcohol Screening (\%) & Drug Screening (\%) \\
\hline Quantity-frequency questions & 25.3 & 34.2 \\
\hline Single screening questions & 18.7 & 43.4 \\
\hline AUDIT-C & 5.3 & - \\
\hline AUDIT & 2.7 & - \\
\hline CAGE & 46.7 & - \\
\hline DAST & - & 0.0 \\
\hline CAGE-AID & - & 11.8 \\
\hline ASSIST & - & 6.0 \\
\hline
\end{tabular}

Abbreviations: AUDIT-C, Alcohol Use Disorders Identification Test-Concise; AUDIT, Alcohol Use Disorders Identification Test; CAGE, Cut Down, Annoyed, Guilty, and Eye Opener; DAST, Drug Abuse Screening Test; CAGE-AID, Cut Down, Annoyed, Guilty, and Eye Opener, Adapted to Include Drug Use; ASSIST, Alcohol, Smoking and Substance Involvement Screening Test. 


\section{Brief Interventions}

When describing the content of their brief interventions, $54 \%$ of postresidency physicians reported that they usually or always included all three key elements of effective brief interventions identified by the US Preventive Services Task Force ${ }^{36}$ : feedback, advice, and goal-setting. This represents a large increase over the $24 \%$ of residents who reported in the baseline survey that they usually or always included all three elements. ${ }^{16}$ Table 3 shows the percentages who reported usually or always performing the specific steps in a typical brief intervention. In their past 50 patients, respondents reported giving advice to quit or cut back a median of five times for alcohol misuse and three for drug misuse, while only a small percentage reported that they had not addressed alcohol (6.8\%) or drug misuse (16.4\%) in any of their past 50 patients. The mean number of minutes spent for interventions for alcohol and drugs was $7.51(\mathrm{SD}=6.02)$ for alcohol, and $7.15(\mathrm{SD}=5.50)$ for drug use.

\section{Referral to Treatment / Follow-up}

Physicians were asked to identify the actions they took when they had a patient who was willing to cut down or quit using alcohol or drugs. Table 4 includes the percentage of physicians reporting that they usually or always took these actions. The most common actions were to refer the patient to a support group (such as Alcoholics Anonymous or Narcotics Anonymous) or counseling rather than a formal treatment program. Discussing medications for treatment of alcohol or drugs was the least common action. As for followup visits, $41 \%$ of physicians reported that they usually or always brought patients back to check on progress related to the patient's alcohol or drug use.

\section{Underlying Attitudes}

The decisional balance portion of the questionnaire was used to assess attitudes or beliefs that might make physicians more or less likely to address alcohol or drug use in their patients. As shown in Table 5, approximately one-third of physicians endorsed the following concerns as either extremely, very, or moderately important in making decisions as to whether to discuss a patient's alcohol/drug use: poor reimbursement, low likelihood of success, lack of time, and, for patients with unhealthy drug use, perceived danger in talking with patients about their substance use. Most postresidency physicians endorsed the following benefits as extremely, very, or moderately important in making decisions as to whether to discuss a patient's alcohol/drug use: interventions can reduce risky use, improve patients' health, prevent future health problems, and improve interpersonal relationships. Few graduates felt alcohol/drug discussions were uncomfortable or threatened doctor-patient relationships, while most felt motivational interviewing techniques created stronger doctor-patient relationships.

Analysis of paired pre/post questionnaire results from 50 physicians indicated statistically significant increases in mean scores on respondents' endorsement of the statement that brief interventions reduced risky use $(P=.002)$ and significant reductions in their endorsement of the statements that they do not have adequate training to address patients' alcohol use $(P<.001)$, that they do not have time to address alcohol use $(P=.036)$, or that discussing alcohol use with patients is uncomfortable $(P=.018)$.

Table 3: Percentage of Postresidency Physicians Reporting "Usually" or "Always" Performing Specific Element in a Brief Intervention

\begin{tabular}{|l|c|c|}
\hline \multicolumn{1}{|c|}{ BI Element } & Unhealthy Alcohol Use (\%) & Drug Use (\%) \\
\hline Providing feedback & 72 & 76 \\
\hline Providing advice to cut back or quit & 83 & 74 \\
\hline Goal-setting & 57 & 58 \\
\hline Emphasizing patient's ability to change & 83 & 85 \\
\hline
\end{tabular}

Abbreviation: BI, brief intervention.

Table 4: Percentage of Postresidency Physicians Who Usually or Always Perform Action With Patient Who Is Ready to Cut Down or Quit Using Alcohol or Drugs

\begin{tabular}{|l|c|c|}
\hline \multicolumn{1}{|c|}{ Action } & Alcohol Use (\%) & Drug Use (\%) \\
\hline Refer to a support group & 51.4 & 46.6 \\
\hline Refer to counseling & 36.6 & 39.7 \\
\hline Refer to formal treatment program & 25.7 & 30.6 \\
\hline Schedule a follow-up visit & 41.1 & 41.7 \\
\hline Prescribe medications & 21.6 & 23.6 \\
\hline
\end{tabular}


Table 5: Making the Decision to Discuss a Patient's Alcohol or Drug Use: Percentage of Postresidency Physicians Indicating the Reason Was Extremely, Very or Moderately Important

\begin{tabular}{|l|c|c|}
\hline \multicolumn{1}{|c|}{ Reason } & Unhealthy Alcohol Use (\%) & Drug Use (\%) \\
\hline Poor reimbursement & 37 & 36 \\
\hline Low likelihood of success & 32 & 30 \\
\hline Lack of time & 33 & 25 \\
\hline Talking with patients about drug use could be dangerous & - & 26 \\
\hline Interventions can reduce risky use & 95 & 86 \\
\hline Interventions can improve patient's health & 95 & 90 \\
\hline Interventions can prevent future health problems & 91 & 91 \\
\hline Interventions can improve interpersonal relationships & 84 & \\
\hline Discussing alcohol/drug use with patients is uncomfortable & 20 & \\
\hline Discussing alcohol/drug use threatens doctor-patient relationship & 20 & 21 \\
\hline Motivational interviewing strengthens doctor-patient relationship & 70 & 20 \\
\hline
\end{tabular}

\section{Discussion}

This study is one of the first to assess the impact of SBIRT training on physicians' attitudes and behaviors following their transition into postresidency practice settings. Residents participated in a longitudinal 3 -year curriculum that provided training with skills practice and included repeated opportunities to use their SBIRT skills in clinical settings which routinely conducted alcohol and drug screening.

\section{Intervention Rates}

An important positive finding was increased reporting of use of all three components of effective brief interventions-feedback, advice to cut back or quit, and negotiating alcohol reduction plans ${ }^{36}$ - when compared with pretraining baseline responses. ${ }^{16}$ Areas for future improvement include increasing referrals to formal treatment programs and greater use of medications for both opioids and alcohol use disorder.

\section{Screening}

The postresidency physicians surveyed reported screening rates of almost $80 \%$ of patients at initial visits. This is particularly impressive in that residents in pretraining surveys by Le reported screening rates of only $60 \%{ }^{16} \chi^{2}$ analyses of the postresidency physicians compared those entering fellowships to those in other types of practice settings and found no statistically significant differences in screening practices (results not shown). Of concern is the fact that the alcohol screening tool most commonly used was the Cut Down, Annoyed, Guilty and Eye Opener (CAGE), which is designed to detect alcohol use disorder, rather than use of quantity-frequency measures and the single alcohol screening question, which are instruments capable of detecting at-risk drinking.

\section{Beliefs About SBIRT \\ Interventions}

Survey results indicated that more than $90 \%$ of postresidency physicians believed interventions reduced risky alcohol and drug use, improved patients' health, and prevented future health problems. They also saw SBIRT as a tool that could improve patients' interpersonal relationships. Pre/post comparisons from the paired sample $(\mathrm{N}=50)$ found that the training increased residents' beliefs that brief intervention can reduce risk from alcohol use and reduced previous perceptions of inadequate training, inadequate time, and discomfort in discussing alcohol use with patients. These findings are consistent with those of Derges et $\mathrm{al}^{37}$ who found that clarity of the intervention, increasing knowledge and skills, and ongoing followup support facilitated effective SBI implementation. While most barriers to providing interventions were endorsed less frequently by clinicians in the postresidency surveys compared to their own pretraining surveys, a minority of the trainee group still had significant concerns. Three issues still noted as significant barriers by roughly one-third of postresidency interviewees were low financial reimbursement, lack of adequate time to devote to interventions, and concerns that conversations about alcohol were unlikely to make a difference for some patients. In addition, $20 \%$ of clinicians continued to feel that discussions about alcohol were uncomfortable. This suggests these issues as important areas to address in future SBIRT training efforts. An important finding is clinicians' belief of the positive impact of motivational interviewing (MI), one component of their training, on clinician-patient relationships. Whereas some previous researchers have expressed significant concerns regarding the negative impact of brief interventions on the doctor-patient relationship, ${ }^{37,38}$ over $70 \%$ of this study's clinicians believed that using their MI skills could actually strengthen the doctorpatient relationship, while less than $30 \%$ felt that discussions about alcohol threatened the doctor-patient relationship. This is an encouraging finding, given that clinician 
emphasis on patients' strengths and belief in their ability to change is a consistent predictor of more positive outcomes. ${ }^{39}$

\section{Impact on the Larger System}

Another important finding was the impact of SBIRT-trained clinicians on the practices they joined. Sixteen percent of graduates reported that they influenced their colleagues and future practices to do SBI, indicating that SBIRT training can have a significant impact on disseminating this important prevention and early intervention strategy as those trained move from residency into fellowships, begin work as hospitalists, or join private practice groups.

\section{Strengths and Limitations}

Strengths of this study include inclusion of postresidency physicians from four residency training programs in three different states and the ability to compare pre- and posttraining data. One limitation of the study is its dependence on self-report data. Data related to the frequency and composition of brief interventions with their last 50 patients is subject to both recall bias and social desirability bias, which might encourage residents to overestimate the number and quality of brief interventions performed. Reports on duration of brief interventions are also subject to recall bias. Another limitation is possible selection bias; despite three attempts to contact all residents after graduation, only $41 \%$ of graduates completed postgraduation assessments and the number of respondents who completed both pre- and posttraining questionnaires was limited. While low survey response rates are not unusual for physicians in practice ${ }^{40}$ and nonresponse rates have been found to be a poor predictor of bias, ${ }^{41}$ it is possible that physicians who had a positive experience with SBIRT training were more likely to respond. Finally, while efforts were made to implement SBIRT training consistently across all sites, residency programs do differ and this could result in some differences in SBIRT training, SBIRT implementation in residency clinics, and, as a result, differences in postgraduate outcomes. Of the four sites, one site that was part of a large academic medical center was significantly larger than the other sites. As a result, more than half of the completed follow-ups were from this site, while the other sites contributed 12-15 respondents each. With only small samples from three of four sites, there is not sufficient statistical power to explore potential cross-site differences.

In conclusion, SBIRT trainees report high levels of SBIRT activity 12-24 months after graduation, and increased SBIRT activities by their colleagues. Residency SBIRT training appears to be a promising approach for disseminating SBIRT into clinical practice.

CORRESPONDING AUTHOR: Please address correspondence to J. Paul Seale, MD, Augusta University, 1120 15th St., Augusta, GA 30912. 706-721-4649. jseale@augusta.edu.

FINANCIAL SUPPORT: This study was funded by Grant 1U79T1020278 from the US Substance Abuse and Mental Health Services Administration (SAMHSA).

PRESENTATIONS: Preliminary findings from this study were presented as follows:

Seale JP, Clark DC, Dhabliwala J, Miller D, Woodall H, Shellenberger S, Johnson JA. Impact of motivational interviewing-based training in screening, brief intervention and referral to treatment on residents' self-reported attitudes and behaviors. $10^{\text {th }}$ conference of INEBRIA (International Network on Brief Interventions for Alcohol and Other Drugs), September 19-20, 2013, Rome, Italy.

Seale JP, Clark DC, Dhabliwala J, Shellenberger S, Johnson A, Miller D, Woodall H. Continued Performance of Alcohol and Drug Screening, Brief Intervention and Referral to Treatment after Residency Graduation: A Pilot Study. North American Primary Care Research Group Annual Meeting, Ottawa, Canada, November 9-13, 2013.

Seale JP, Johnson JA, Shellenberger S. Increasing Impact of Longitudinal Training on Residents' Confidence and Performance of Alcohol Screening and Brief Intervention. Association for Medical Education in Substance Abuse (AMERSA) Annual Meeting, Washington, DC, November 5-7, 2015.

\section{References}

1. Costs of Substance Abuse. National Institute on Drug Abuse. Accessed October 14, 2020. https://www.drugabuse.gov/drug-topics/trendsstatistics/costs-substance-abuse

2. US Department of Health and Human Services (HHS), Office of the Surgeon General. Facing addiction in America: The surgeon general's report on alcohol, drugs, and health. Washington, DC: HHS; 2016.

3. Substance Abuse and Mental Health Services Administration. Key substance use and mental health indicators in the United States: Results from the 2019 National Survey on Drug Use and Health. Rockville, MD: HHS; 2020.

4. Curry SJ, Krist AH, Owens DK, et al; US Preventive Services Task Force. Screening and behavioral counseling interventions to reduce unhealthy alcohol use in adolescents and adults: U.S. Preventive Services Task Force recommendation statement. JAMA. 2018;320(18):18991909. doi:10.1001/jama.2018.16789

5. D'Amico EJ, Paddock SM, Burnam A, Kung F-Y. Identification of and guidance for problem drinking by general medical providers: results from a national survey. Med Care. 2005;43(3):229-236. doi:10.1097/00005650200503000-00005

6. McGlynn EA, Asch SM, Adams J, et al. The quality of health care delivered to adults in the United States. N Engl J Med. 2003;348(26):2635-2645. doi:10.1056/NEJMsa022615

7. McKnight-Eily LR, Liu Y, Brewer RD, et al; Centers for Disease Control and Prevention (CDC). Vital signs: communication between health professionals and their patients about alcohol use -44 states and the District of Columbia, 2011. MMWR Morb Mortal Wkly Rep. 2014;63(1):16-22.

8. Hingson RW, Heeren T, Edwards EM, Saitz $\mathrm{R}$. Young adults at risk for excess alcohol consumption are often not asked or counseled about drinking alcohol. J Gen Intern Med. 2012;27(2):179-184. doi:10.1007/s11606-0111851-1

9. Scialli AC, Terplan M. Rates of and factors associated with patient-reported illicit drug use screening by health care professionals in the United States from 2013 to 2015. J Addict Med. 2020;14(1):63-68. doi:10.1097/ ADM.0000000000000537

10. McKnight-Eily LR, Okoro CA, Turay K, Acero C, Hungerford D. Screening for alcohol use and brief counseling of adults - 13 states and the District of Columbia, 2017. MMWR Morb Mortal Wkly Rep. 2020;69(10):265-270. doi:10.15585/mmwr.mm6910a3

11. Glass JE, Bohnert KM, Brown RL. Alcohol screening and intervention among United States adults who attend ambulatory healthcare. J Gen Intern Med. 2016;31(7):739-745. doi:10.1007/s11606-016-3614-5

12. Screening, Brief Intervention, and Referral to Treatment (SBIRT) Grantees. Substance Abuse4 and Mental Health Services Administration. Accessed October 16, 2020 https://www. samhsa.gov/sbirt/grantees 
13. Tetrault JM, Green ML, Martino S, et al. Developing and implementing a multispecialty graduate medical education curriculum on Screening, Brief Intervention, and Referral to Treatment (SBIRT). Subst Abus. 2012;33(2):168-181. doi:10.1080/08897077.201 1.640220

14. Bray JH, Kowalchuk A, Waters V, Laufman L, Shilling EH. Baylor SBIRT Medical Residency Training Program: model description and initial evaluation. Subst Abus. 2012;33(3):231-240. doi:10.1080/08897077.2011.640160

15. Seale JP, Velasquez MM, Johnson JA, et al. Skills-based residency training in alcohol screening and brief intervention: results from the Georgia-Texas "Improving Brief Intervention" Project. Subst Abus. 2012;33(3):261-271. doi:10.1080/08897077.2011.640187

16. Le KB, Johnson JA, Seale JP, et al. Primary care residents lack comfort and experience with alcohol screening and brief intervention: a multi-site survey. J Gen Intern Med. 2015;30(6):790-796. doi:10.1007/s11606-015$3184-\mathrm{y}$

17. Clemence AJ, Balkoski VI, Lee M, et al. Residents' experience of screening, brief intervention, and referral to treatment (SBIRT) as a clinical tool following practical application: A mixed-methods study. Subst Abus. 2016;37(2):306-314. doi:10.1080/08897077.20 15.1064850

18. Clemence AJ, Balkoski VI, Schaefer BM, et al. Multispecialty screening, brief intervention, and referral to treatment (SBIRT) training in an academic medical center: resident training experience across specialties. Subst Abus. 2016;37(2):356-363. doi:10.1080/08897077.201 5.1082953

19. Marshall VJ, McLaurin-Jones TL, Kalu N, et al. Screening, brief intervention, and referral to treatment: public health training for primary care. Am J Public Health. 2012;102(8):e30-e36. doi:10.2105/AJPH.2012.300802

20. Pringle JL, Kowalchuk A, Meyers JA, Seale JP. Equipping residents to address alcohol and drug abuse: the national SBIRT residency training project. J Grad Med Educ. 2012;4(1):58-63. doi:10.4300/JGMED-11-00019.1

21. Kalu N, Cain G, Mc-Laurin-Jones T, et al. Impact of a multi-component SBIRT training curriculum on a medical residency program. Subst Abus. 2016;37(1):242-247. doi:10.1080/0 8897077.2015.1035841

22. Gotham HJ, Knopf-Amelung S, Krom L, Stilen P, Kohnle K. Competency-based SBIRT training for health-care professionals: nursing and social work students. Addict Sci Clin Pract. 2015;10(S1)(suppl 1):A14. doi:10.1186/19400640-10-S1-A14
23. Bray JW, Del Boca FK, McRee BG, Hayash SW, Babor TF. Screening, Brief Intervention and Referral to Treatment (SBIRT): rationale, program overview and cross-site evaluation. Addiction. 2017 Feb;112 Suppl 2:3-11. doi: 10.1111/add.13676

24. Hettema JE, Ratanawongsa N, Manuel JK, Ciccarone D, Coffa D, Jain S, \& Lum PJ. A SBIRT curriculum for medical residents: Development of a performance feedback tool to build learner confidence. Substance Abuse. 2012;33(3):241-250. doi: 10.1080/08897077.2011.640172

25. Malone GP, Vale S, Schneegans S, et al. South Texas residency SBIRT training: 12-month outcomes. Substance Abuse. 2015;36(3). doi:1 0.1080/08897077.2014.988839

26. Muench J, Jarvis K, Boverman J, Hardman J, Hayes M, Winkle J. Tilling the soil while sowing the seeds: combining resident education with medical home transformation. Subst Abus. 2012;33(3):282-285. doi:10.1080/0889707 7.2011 .640088

27. Seale JP, Johnson JA, Clark DC, et al. A multisite initiative to increase the use of alcohol screening and brief intervention through resident training and clinic systems changes. Acad Med. 2015;90(12):1707-1712. doi:10.1097/ ACM.0000000000000846

28. Smith PC, Schmidt SM, Allensworth-Davies D, Saitz R. Primary care validation of a singlequestion alcohol screening test. J Gen Intern Med. 2009;24(7):783-788. doi:10.1007/s11606009-0928-6

29. Smith PC, Schmidt SM, Allensworth-Davies D, Saitz R. A single-question screening test for drug use in primary care. Arch Intern Med. 2010;170(13):1155-1160. doi:10.1001/archinternmed.2010.140

30. Saunders JB, Aasland OG, Babor TF, de la Fuente JR, Grant M. Development of the Alcohol Use Disorders Screening Test (AUDIT): WHO Collaborative project on early detection of persons with harmful alcohol consumption-II. Addiction. 1993;88(6):791-804. doi:10.1111/j.1360-0443.1993.tb02093.x

31. Skinner HA. The drug abuse screening test. Addict Behav. 1982;7(4):363-371. doi:10.1016/0306-4603(82)90005-3

32. Bernstein J, Bernstein E, Tassiopoulos K, Heeren T, Levenson S, Hingson R. Brief motivational intervention at a clinic visit reduces cocaine and heroin use. Drug Alcohol Depend. 2005;77(1):49-59. doi:10.1016/j.drugalcdep.2004.07.006

33. D’Onofrio G, Fiellin DA, Pantalon MV, et al. A brief intervention reduces hazardous and harmful drinking in emergency department patients. Ann Emerg Med. 2012;60(2):181-192. doi:10.1016/j.annemergmed.2012.02.006
34. Anderson P, Clement S. The AAPPQ revisited: the measurement of general practitioners' attitudes to alcohol problems. Br J Addict. 1987;82(7):753-759. doi:10.1111/j.1360-0443.1987.tb01542.x

35. Mayfield D, McLeod G, Hall P. The CAGE questionnaire: validation of a new alcoholism screening instrument. Am J Psychiatry. 1974;131(10):1121-1123.

36. Whitlock EP, Polen MR, Green CA, Orleans T, Klein J; U.S. Preventive Services Task Force. Behavioral counseling interventions in primary care to reduce risky/harmful alcohol use by adults: a summary of the evidence for the U.S. Preventive Services Task Force. Ann Intern Med. 2004;140(7):557-568. doi:10.7326/00034819-140-7-200404060-00017

37. Derges J, Kidger J, Fox F, Campbell R, Kaner E, Hickman M. Alcohol screening and brief interventions for adults and young people in health and community-based settings: a qualitative systematic literature review. BMC Public Health. 2017;17(1):562. doi:10.1186/ s12889-017-4476-4

38. Beich A, Gannik D, Malterud K. Screening and brief intervention for excessive alcohol use: qualitative interview study of the experiences of general practitioners. BMJ. 2002;325(7369):870. doi:10.1136/ bmj.325.7369.870

39. Miller WR, Rollnick S. Motivational interviewing: preparing people for change. 2nd ed. New York, NY: Guilford Press; 2002.

40. James KM, Ziegenfuss JY, Tilburt JC, Harris AM, Beebe TJ. Getting physicians to respond: the impact of incentive type and timing on physician survey response rates. Health Services Research. 2011 Feb;46(1p1):232-42. doi:10.1111/j.1475-6773.2010.01181.x

41. Groves RM, Peytcheva E. The impact of nonresponse rates on nonresponse bias: a metaanalysis. Public Opin Q. 2008;72(2):167-189. doi:10.1093/poq/nfn011 